\title{
A concentração espacial do Programa Cultura Viva no município do Rio de Janeiro ${ }^{1}$
}

\author{
La concentración espacial del Programa Cultura Viva en el municipio del \\ Río de Janeiro
}

\author{
The spatial concentration of the Cultura Viva program in the city of Rio de \\ Janeiro
}

Bruno Costa Guimarães ${ }^{2}$

\begin{abstract}
Resumo
A lei 8.313 de 1991, Lei Rouanet, é a principal forma de promoção de projetos culturais no Brasil. Sua criação, no contexto da reabertura democrática do país após a ditadura militar, teve como um de seus objetivos diminuir a centralidade do papel do Estado na cultura e ampliar o poder de decisão do mercado privado. Para esse fim, os empresários decidiram quais projetos financiariam, sendo recompensados com isenções de impostos. Naturalmente, esse processo levou à centralidade dos projetos culturais nas grandes cidades, notadamente na região Sudeste. Para contrabalançar isso, em 2004, o governo do Partido dos Trabalhadores estabeleceu um programa que reintroduziu o papel decisório do governo na cultura, o Programa Cultura Viva, com o objetivo de descentralizar geograficamente projetos culturais. A observação, no entanto, é que dentro do Estado do Rio de Janeiro, a capital ainda tem grande poder de centralização.
\end{abstract}

Palavras-Chave: Cultura Viva; Lei Rouanet ; Políticas Públicas.

\section{Resumen}

La Ley 8.313 de 1991, Ley Rouanet, es la principal forma de fomento a proyectos culturales en Brasil. Su creación, en el contexto de la reapertura democrática del país tras la dictadura militar, tenía como uno de sus objetivos disminuir la centralidad del papel del Estado en la cultura y expandir el poder de decisión del mercado privado. Para este fin, los empresarios decidían qué proyectos iban a financiar, siendo recompensados con exenciones fiscales. Naturalmente, este proceso acarreó en centralidad de proyectos culturales en las grandes ciudades, notadamente en la región Sudeste. Para contrarrestar esto, en 2004, el gobierno del Partido de los Trabajadores establece un programa que reintegra el papel decisorio del gobierno en la cultura, el Programa Cultura Viva, con el objetivo de descentralizar geográficamente los proyectos culturales. El observado, sin embargo, es que dentro del Estado de Río de Janeiro, la ciudad capital todavía tiene gran poder de centralización.

Palabras claves: Cultura Viva ; Ley Rouanet ; Políticas Públicas

\section{Abstract}

The law 8.313 of 1991, Lei Rouanet, is the main form of promotion to cultural projects in Brazil. Its creation, in the context of the democratic reopening of the country after the military dictatorship, had as one of its objectives

1 Artigo apresentado no II Seminário Latino-Americano de Estudos em Cultura - SEMLACult em Foz do Iguaçu/PR, Brasil, 2018.

2 Doutorando em Geografia; Universidade Federal do Rio de Janeiro; Rio de Janeiro, RJ, Brasil ; bruno.costag@gmail.com”. 
to diminish the centrality of the role of the State in the culture and to expand the power of decision of the private market. To this end, businessmen decided which projects they would finance, being rewarded with tax exemptions. Naturally, this process has led to the centrality of cultural projects in large cities, notably in the Southeast region. To counterbalance this, in 2004, the Workers' Party government established a program that reintroduced the government's decision-making role in culture, the Cultura Viva Program, with the objective of geographically decentralizing cultural projects. The observation, however, is that within the State of Rio de Janeiro, the capital city still has great power of centralization.

Keywords: Cultura Viva ; Rouanet Law ; Public Policies.

\section{Introdução}

Ao estudarmos os diferentes momentos das políticas culturais no Brasil, nos deparamos com algumas mudanças de paradigmas. Passamos por um período de tutela, de fomento reduzido, das artes eruditas (SODRÉ, 1985) para, recentemente, o da forte participação do mercado através das políticas de dedução fiscal da lei Rouanet (década de 90). Uma mudança veio a partir de 2004, nas gestões dos ministros Gilberto Gil e Juca Ferreira, quando o programa Cultura Viva trouxe para o foco do Ministério da Cultura a cultura latente na vivência do brasileiro e iniciou um processo com o intuito de retirar o estigma pejorativo da cultura popular como "folclore" (em uma oposição negativa ao eruditismo).

As políticas culturais cumprem um papel importante na construção de um processo institucional e discursivo que promova grupos renegados e membros de culturas marginalizadas para que estes se tornem capazes de expor suas demandas e necessidades, bem como preservar as práticas dentro das quais tecem suas identidades e aspirações (VENTURA, 2009). É por este motivo que nos propomos a realizar uma análise da distribuição espacial dos dois tipos principais de fomento a projetos culturais: o mecenato da Lei Rouanet e o programa Cultura Viva, e levantar questionamentos acerca dos discursos e territorialidades de sua distribuição no estado do Rio de Janeiro.

É importante, então, definirmos política cultural. Como explica Coelho:

"[...]a política cultural é entendida habitualmente como programa de intervenções realizadas pelo Estado, instituições civis, entidades privadas ou grupos comunitários com o objetivo de satisfazer as necessidades culturais da população e promover o desenvolvimento de suas representações simbólicas" (COELHO, 2004, p. 293)

Como elabora o autor, o Estado interage com a cultura ao realizar intervenções por meio das políticas culturais, que podem ser categorizadas em duas formas:

1- $\quad$ Normas jurídicas, no caso do Estado, ou procedimentos tipificados, em relação aos demais agentes, que regem as relações entre os diversos sujeitos e objetos culturais. 
2- $\quad$ Intervenções diretas de ação cultural no processo cultural propriamente dito.

\section{Contextualização:}

As Políticas culturais no Brasil possuem um histórico bastante entrelaçado com o caráter heterogêneo dos diversos governos que se seguiram ao longo do século $\mathrm{XX}$. Os períodos de autoritarismo, militarismo, abertura mercadológica, todos imprimiram um caráter distinto às políticas que definiram a forma como o Estado deveria enxergar o tratamento da cultura. Desta forma, a comparação estabelecida entre os dois mecanismos de fomento à cultura analisados, o mecenato e o programa cultura viva, não podem ser dissociados dos governos e do contexto histórico no qual foram criados.

O primeiro período político que demonstra uma inserção atenta do Estado na elaboração de um sistema político da cultura pode ser enxergado como o Estado Novo de Getúlio Vargas (Calabre, 2005). Nesse período, marcado por seu caráter centralizador, o Estado foi redefinido como uma entidade que se fortaleceu e expandiu sua área de atuação, entrando em campos que anteriormente não eram de sua capacidade, entre estes, a cultura. Um dois exemplos é o do campo da preservação do patrimônio material com a fundação do Serviço do Patrimônio Histórico e Artístico Nacional (Sphan). Outros exemplos do mesmo período incluem a criação do Instituto Nacional do Cinema Educativo (Ince) a ampliação do mercado editorial com a formação do Instituto Nacional do Livro (INL). Outro importante elemento que deve ser mencionado é a preferência pelo veículo de divulgação cultural com o incentivo ao rádio. O decreto lei 21.111 de 1932 regulamentou a radiodifusão, normatizou questões como a veiculação de publicidade, formação de técnicos e potência de equipamentos. No aspecto burocrático, a cultura encontrava-se sob o guarda-chuva do Ministério da Educação e Saúde (MES). Merecem menção o ministro Gustavo Capanema e sua gestão de 1934 até 1945. Nesse período, Capanema estendeu seu interesse artístico marcado pelo modernismo sobre a política cultural do país e foi pioneiro ao enxergar a cultura como um elemento progressista capaz de beneficiar a nação através da formação do cidadão brasileiro, e portanto, a elaboração de uma política cultural era vista como alicerce para o desenvolvimento do país. Esta tradição, esta forma de enxergar a cultura como um saber norteador para a elaboração de um senso de identidade, união e progresso, é repetida tipicamente em governos caracterizados pelo regime autoritário, nacionalista e ufanista. 
Findo o período do Estado Novo, o vácuo gerado pela queda de um regime autoritário foi preenchido pela participação da iniciativa privada na elaboração de políticas e ações culturais. É importante notar que este ciclo se repetiu décadas depois com a ascensão ao poder dos militares e sua subsequente queda. A instabilidade política do Brasil no século passado deixou como herança a alternância entre autoritarismo e ausência (que é preenchida pelo mercado e a iniciativa privada).

Entre 1945 e 1964, o Estado não exerceu papel protagonista na elaboração de políticas ou ações culturais; estas foram relegadas à iniciativa privada. Em 1950, a televisão chegou ao Brasil em consequência do fim da Segunda Guerra Mundial, o que permitiu a retomada da produção em massa de rádios e televisores. Com relação ao papel do Estado, o Ministério da Saúde e Educação foi desmembrado, dividindo suas atribuições entre o Ministério da Saúde (MS) e o Ministério da Educação e Cultura (MEC).

O próximo período histórico foi marcado pela chegada dos militares ao poder em 1964, iniciando um novo ciclo de governos autoritários que tratariam a cultura de forma centralizada e difusora novamente. Não era reconhecido que o povo fosse capaz de produzir e vivenciar sua própria cultura. O Estado promovia a cultura em vez de reconhecê-la.

O período militar foi marcado pela criação de órgãos, planos de ação e financiamento. Houve a criação do Plano de Ação Cultural (PAC) sob a gestão do ministro Jarbas Passarinho (1969-1973), durante o governo Médici, que consistia na abertura de crédito para financiar projetos culturais. Novos órgãos foram estabelecidos, como o Conselho Nacional de Direito Autoral (CNDA), o Conselho Nacional de Cinema, a Campanha de Defesa do Folclore Brasileiro, a Fundação Nacional de Arte (FUNARTE). Ocorreu ainda a reformulação da Embrafilme, que havia sido criada em 1969.

O caráter centralizador do Estado no campo da cultura tornou-se especialmente evidente em 1976, quando foi lançado o Plano Nacional da Cultura (PNC), cujo objetivo era estabelecer um sistema de coordenação e elaboração de ações culturais promovidas de acordo com a visão estatal de cultura. Também se iniciou nesta época uma discussão em relação à possibilidade de criação de um Ministério exclusivo para a cultura:

"Diante do claro fortalecimento do setor cultural, surge dentro da Secretaria de Cultura uma grande discussão entre um grupo que apoiava a ideia da criação do Ministério da Cultura e outro que desejava a ampliação da estrutura de secretaria dentro do MEC. O segundo grupo temia que a desvinculação do Ministério da Educação resultasse em recuo do processo de crescimento que estava em curso. Para esse grupo, era preferível estar em uma secretaria forte do que em um ministério fraco.” (CALABRE, 2005, p. 15) 
A resolução dessa discussão veio em 1986 com a criação do Ministério da Cultura. Como previsto por alguns, as verbas ficaram majoritariamente com a educação, desfavorecendo o desenvolvimento de políticas promissoras na cultura. O novo ministério foi criado acompanhado de uma série de problemas: perda de autonomia, superposição de poderes, ausência de linhas de atuação política, disputa de cargos, clientelismo.

O fim do regime militar e a abertura política marcaram um novo ciclo em que o Estado se retirou do campo de formulação de políticas culturais e a iniciativa privada surgiu para preencher o consequente vácuo. Em especial com a Constituição de 1988, foi rejeitada a ideia de um Estado impositor e autoritário, tornando promissor o campo para a ação de empreendedores privados, que assumiram o papel de norteadores da cultura. Do vácuo deixado pela ditadura surgiram as primeiras políticas de incentivo à cultura. Em 1985, o presidente José Sarney promulgou a lei $\mathrm{n}^{\mathrm{o}} 7.505$, conhecida como Lei Sarney, que funcionava a partir de isenções fiscais para atrair investidores a injetar dinheiro em projetos culturais. Em 1990, o governo Collor extinguiu a Lei Sarney, mas reestruturou o projeto de incentivos fiscais por meio da Lei Rouanet.

Uma diferença entre os dois mecanismos é que durante a vigência da Lei Sarney a prestação de contas entre o arrecadador e o Ministério da Cultura era uma peça da pósprodução do evento, ao contrário do que se tornou com a Lei Rouanet, onde o projeto é julgado em sua fase inicial à luz do orçamento que consumirá. Com a Lei Rouanet, estabeleceu-se o Programa Nacional de Apoio à Cultura - PRONAC. O principal mecanismo de arrecadação financeira do PRONAC é a renúncia fiscal, na qual pessoas físicas ou jurídicas podem destinar uma parcela do Imposto de Renda ao apoio à cultura e, em retorno, terá parte deste valor deduzido do imposto de renda, desde que esta parte não ultrapasse $4 \%$ do valor total de imposto devido para pessoas jurídicas e 6\% para pessoas físicas (BRASIL, 1991) . Este tipo de financiamento utiliza recursos públicos de forma indireta, pois se trata de dinheiro que seria recolhido de impostos pelo governo. De acordo com as instruções do MinC, a proposta cultural deve ser analisada e aprovada pela Comissão Nacional de Incentivo à Cultura - CNIC. Após a publicação da aprovação do projeto no Diário Oficial, o proponente passa à condição de beneficiário e a proposta à condição de projeto. A partir daí, o apoio através deste mecanismo pode se dar de duas formas, enquadrando-se em dois artigos distintos:

-Artigo 26: ao enquadrar-se no artigo 26, é permitido que o doador ou patrocinador deduza do Imposto de Renda os valores contribuídos em favor de projetos culturais aprovados. No caso 
de o financiador ser pessoa física, a dedução será de $80 \%$, para as doações, e de $60 \%$, para patrocínios.

-Artigo 18: Permite dedução de $100 \%$ do valor aplicado se os projetos se encaixarem nas seguintes categorias: a) artes cênicas; b) livros de valor artístico, literário ou humanístico; c) música erudita ou instrumental; d) exposições de artes visuais; e) doações de acervos para bibliotecas públicas, museus, arquivos públicos e cinematecas, bem como treinamento de pessoal e aquisição de equipamentos para a manutenção desses acervos; f) produção de obras cinematográficas e videofonográficas de curta e média metragem e preservação e difusão do acervo audiovisual; g) preservação do patrimônio cultural material e imaterial; h) construção e manutenção de salas de cinema e teatro, que poderão funcionar também como centros culturais comunitários, em municípios com menos de 100 mil habitantes. (BRASIL, 1991)

Em 2004, o Programa Nacional de Cultura, Arte e Cidadania - Cultura Viva - foi criado. Sua principal iniciativa - os Pontos de Cultura - tem como objetivo diminuir as desigualdades regionais da cultura amparando-se nos pressupostos de participação e descentralização. Os Pontos de Cultura foram pensados com uma proposta diferente da renúncia fiscal. A ideia era reconhecer e valorizar as diversas formas de manifestação cultural no Brasil e dar a elas o fomento necessário para que tivessem inserção econômica e diálogo com a sociedade.

O espaço físico do Ponto de Cultura pode ser uma casa, um barracão, um centro cultural, um museu, uma escola. O fundamental é priorizar o protagonismo social.

"No que se refere ao público foco, este foi definido como as populações de baixa renda, que habitam áreas com precária oferta de serviços públicos, tanto nos grandes centros urbanos como nos pequenos municípios, adolescentes e jovens adultos em situação de vulnerabilidade social; estudantes da rede básica de ensino público; habitantes de regiões e municípios com grande relevância para a preservação do patrimônio histórico, cultural e ambiental brasileiro; comunidades indígenas, rurais e remanescentes de quilombos, agentes culturais, artistas e produtores, professores e coordenadores pedagógicos da educação básica e militantes sociais que desenvolvem ações de combate à exclusão social e cultural.” (BRASIL, 2004)

A proposta do Cultura Viva é ideologicamente distinta do mecenato. A expressão “cidadania cultural” merece ser citada para entender o princípio guia do programa.

“As diretrizes básicas da cidadania cultural se referem à universalização do acesso aos bens e serviços culturais com base no direito de todo cidadão de produzir cultura, ser criador e transformador de símbolos; participar das decisões políticas e do processo de gestão pública da cultura; ter acesso aos sistemas públicos de informação, por meio dos quais se manterá informado sobre os serviços culturais e 
sobre a realidade cultural de seu país; ter formação cultural e artística em esferas públicas e privadas; ter espaços para reflexão e debate; ter acesso à infraestrutura tecnológica para produção e divulgação em diferentes mídias; usufruir do direito à informação e à comunicação, que abrange o direito de produzir informação e divulgá-la; assim como o direito à diferença, que significa tanto ter oportunidades de descobrir a variedade de culturas que compreendem o patrimônio de sua sociedade e da humanidade. Como exprimir sua própria cultura de forma diferenciada, longe de coibição ou subordinação.” (BARROS \& ZIVIANI, 2011, p. 63)

A partir da gestão de Gilberto Gil, no entanto, o papel do Estado adquiriu um caráter misto na forma de enxergar a cultura. Em um cenário bastante peculiar, atualmente nos encontramos na vigência de duas políticas culturais, sob as formas de incentivo e fomento à cultura, que veem o papel do Estado de maneiras bastante distintas.

Quando comparamos os valores do incentivo fiscal ao total do valor disponibilizado, é visível a predominância da dedução de impostos como estratégia de política de financiamento público, o que permite concluir que a maior parte da cultura no Brasil é submetida à lógica do mercado. Pelas leis de incentivo, o proponente solicita um determinado valor, que, após as reformas feitas pela instrução normativa $n^{\circ} 2$ de 23 de abril de 2019 , teve o teto ampliado para 100 milhões para Empresas Individuais de Responsabilidade Limitada (EIRELI), Sociedades Limitadas (Ltda), Organizações da Sociedade Civil de Interesse Público e demais pessoas jurídicas (este é o maior teto disposto a uma categoria de proponente pela lei de incentivo). A classificação de proponente com teto mais baixo, os microempresários individuais, podem solicitar até 10 milhões por projeto. Já nos Pontos de Cultura, este valor é fixo e bem inferior ao da isenção fiscal. Como explica Dornelles:

“Cada instituição cultural que se torna um Ponto de Cultura recebe do governo um recurso de cento e oitenta mil reais. Parte deste recurso deve ser investida em kits multimídias elaborados a partir da necessidade de cada projeto de Ponto de Cultura." (DORNELLES, 2011, p. 209)

Adicione-se à citação que as parcelas são semestrais e valem por um período total de dois anos e meio. Observamos, então, uma distinção muito básica entre a dedução fiscal e os Pontos de Cultura. A primeira é submetida a interesses privados na seleção dos projetos aptos a arrecadar fundos. Já os Pontos de Cultura são pautados em princípios inovadores ao inserirem na discussão da cultura outras duas dimensões das políticas públicas, além da econômica: a representação simbólica e a participação e cidadania.

O ano de 2007 foi importante para o programa Cultura Viva e seu processo de expansão territorial, pois foi quando ocorreu a descentralização de seus editais para estados e 
municípios. Os efeitos desta política e a relevância da descentralização para o aumento do alcance do Cultura Viva são o cerne do artigo e serão discutidos posteriormente.

Em 2015, o montante financeiro autorizado a ser captado por meio de leis de incentivo ultrapassou a faixa de 5,2 bilhões de reais (PORTAL BRASIL, 2016), enquanto o programa Cultura Viva obteve o valor total de 548 milhões de reais, de sua criação, em 2004, até o ano de 2015 (BRAGA, 2014). Por esta razão, o Cultura Viva precisou utilizar estratégias mais elaboradas para expandir sua rede de ações, o que envolveu diretamente o papel do Estado em descentralizar os editais promotores do financiamento de Pontos de Cultura para outros municípios e estados.

\title{
3. Problematização:
}

A proposta do Cultura Viva está assentada em uma lógica distinta do mecenato. A expressão “cidadania cultural” merece ser citada para entender o princípio guia do programa.

\begin{abstract}
"As diretrizes básicas da cidadania cultural se referem à universalização do acesso aos bens e serviços culturais com base no direito de todo cidadão de produzir cultura, ser criador e transformador de símbolos; participar das decisões políticas e do processo de gestão pública da cultura; ter acesso aos sistemas públicos de informação, por meio dos quais se manterá informado sobre os serviços culturais e sobre a realidade cultural de seu país; ter formação cultural e artística em esferas públicas e privadas; ter espaços para reflexão e debate; ter acesso à infraestrutura tecnológica para produção e divulgação em diferentes mídias; usufruir do direito à informação e à comunicação, que abrange o direito de produzir informação e divulgá-la; assim como o direito à diferença, que significa tanto ter oportunidades de descobrir a variedade de culturas que compreendem o patrimônio de sua sociedade e da humanidade. Como exprimir sua própria cultura de forma diferenciada, longe de coibição ou subordinação" (BARROS \& ZIVIANI, 2011, p. 63)
\end{abstract}

A Lei Rouanet trouxe para o campo da produção cultural um montante financeiro expressivo através da parceria com a iniciativa privada. No entanto, a captação de recursos financeiros por meio de dedução de impostos acabou subjugando a produção de cultura aos interesses de empresários. O retorno deste investimento ocorre de diversas maneiras, como: reforçara postura de empresa cidadã; construindo a imagem da sua marca; aumentando sua credibilidade; benefícios fiscais e outras formas que melhoram a imagem da empresa para o público e oferecem vantagens financeiras (BELING, 2004).

Essas vantagens dependem do alcance do produto cultural ao público. Devido à desigualdade regional brasileira, ocorre uma concentração espacial da cultura no sudeste 
(principalmente Rio e São Paulo), pois é onde os investidores conseguirão maior visibilidade e, portanto, são aprofundados os contrastes entre as regiões (DÓRIA, 2003). Dados e análises do próprio MinC revelam que, no ano de 2003, $70 \%$ do valor aprovado dos recursos da renúncia fiscal foram destinados a projetos na região Sudeste e dentro do próprio Sudeste, a concentração ainda ocorre em escala municipal. Dos vinte municípios que concentraram a demanda no MinC em 2007, 16 deles são capitais de estado (SANTOS, 2011).

Por ter uma proposta diferente, o Programa Cultura Viva pauta a distribuição geográfica dos pontos contemplados com o fomento por três variáveis: IDH, dados quantitativos da população e envio de propostas (TURINO, 2009). O que observamos por meio da Munic de 2014 é que, apesar disso, permanece uma característica comum às duas formas de fomento: a concentração. Os Pontos de Cultura se apresentaram distribuídos de forma desigual no estado do Rio de Janeiro, concentrando-se na capital. O Cultura Viva exibe um padrão de distribuição espacial amplo quando observamos a criação de novos Pontos de cultura utilizando a escala nacional. Quando transferimos o mesmo problema para a escala estadual, no entanto, encontramos uma grande desproporção de pontos de cultura concentrados na capital, uma concentração que extrapola as justificativas que poderiam ser apresentadas devido à sua maior população.

A observação dos projetos culturais que foram financiados pela renúncia fiscal em 2014 não apresentou nenhuma distribuição fora do padrão: Foram propostos 1314 projetos para o estado do Rio de Janeiro, dos quais 1213 são propostas localizadas na capital, aproximadamente $92 \%$. Até então, este resultado era esperado, uma vez que o sistema de renúncia favorece a concentração cultural onde o patrocinador irá obter maior retorno à sua marca. Como há uma grande metropolização por parte da capital dentro do estado, nenhuma surpresa que a cidade do Rio de Janeiro abarca um imenso montante dos investimentos culturais.

O contrapeso a esta concentração, deveria então ser o programa Cultura Viva com seus Pontos de Cultura, lembrando novamente que a equação de quais unidades da federação devem receber o apoio do programa envolve o IDH, a população e o envio de propostas, gerando assim um índice que visa a proporcionalidade de pontos pelo território. Esta proporcionalidade não ocorre quando transferimos a escala de estado para municípios do Rio de Janeiro: a capital afirmou que apresenta 165 pontos de cultura. O município a apresentar o segundo maior número, Nova Friburgo, respondeu que possui 6 pontos de cultura. Os demais apresentam números que giram em torno de 2 e 3, e um número substancial não apresenta nenhum. Pelo peso populacional, a capital naturalmente teria um número maior de pontos. 
Com relação ao IDH, a capital possui o segundo maior, atrás de Niterói , portanto não necessita de uma política cultural privilegiada em relação aos demais por esta variável. A população, que tem impacto sobre o número de propostas, deveria então, por si, explicar a concentração. Mesmo assim, há discrepâncias. O total de habitantes da capital representa 39\% do número de habitantes do estado, mas seus pontos de cultura extrapolam esta proporção, com $60,8 \%$ dos Pontos de Cultura totais.

Para compreender o fenômeno da capitalidade que concentra os Pontos de Cultura no Rio de Janeiro, foi elaborada uma tabela comparativa com os outros estados da região Sudeste, a fim de constatar se a capital fluminense é um caso a parte ou se tal concentração é natural.

A tabela consiste na comparação de dois tipos de concentração: a de pontos de cultura e a de população. Presume-se que, sendo o quantitativo demográfico um dos fatores determinantes na implementação das ações do Cultura Viva (Turino, 2009), a capital, que geralmente é o município com maior população, apresente uma relação proporcional entre a concentração de pontos e a concentração de habitantes. Assim sendo, se a concentração de pontos de cultura na capital for superior a de população, resultando em uma diferença positiva, pode-se afirmar que há uma concentração desproporcional de pontos. Abaixo, os resultados deste cálculo:

Tabela 1 - Comparação entre as duas políticas culturais

\begin{tabular}{|c|c|c|c|c|c|c|}
\hline ESTADO & $\begin{array}{c}\mathrm{N}^{\circ} \mathrm{de} \\
\text { municípios }\end{array}$ & $\begin{array}{c}\mathrm{N}^{\mathrm{o}} \mathrm{de} \\
\text { Pontos de } \\
\text { Cultura }\end{array}$ & $\begin{array}{c}\% \text { de } \\
\text { Pontos na } \\
\text { capital }\end{array}$ & Pop. Total & $\begin{array}{c}\% \text { da Pop na } \\
\text { capital }\end{array}$ & $\begin{array}{c}\text { Diferença de } \\
\text { concentração de } \\
\text { Pontos e } \\
\text { População }\end{array}$ \\
\hline $\begin{array}{c}\text { MINAS } \\
\text { GERAIS }\end{array}$ & 853 & 306 & $8,16 \%$ & 21.119 .536 & $11,9 \%$ & $-3,4$ \\
\hline $\begin{array}{c}\text { ESPÍRITO } \\
\text { SANTO }\end{array}$ & 78 & 51 & $9,8 \%$ & 3.973 .697 & $9,1 \%$ & $+0,7$ \\
\hline SÃO PAULO & 645 & 493 & $17,2 \%$ & 44.749 .699 & $27 \%$ & $-9,8$ \\
\hline $\begin{array}{c}\text { RIO DE } \\
\text { JANEIRO }\end{array}$ & 92 & 271 & $60,8 \%$ & 16.635 .966 & $39,1 \%$ & $+21,7$ \\
\hline
\end{tabular}

Fonte: autoria própria com dados do IBGE.

Como é possível observar, a concentração de pontos no Rio de Janeiro ultrapassa, e muito, sua concentração de habitantes. 
Em um país que apresenta grande diversidade socioeconômica como o Brasil, a relação entre a cultura e o território é bastante enlaçada. Tornar uma política cultural eficiente é, também, descentralizá-la. Compreendemos como "Descentralização Cultural":

\footnotetext{
"Processo pelo qual comunidades locais -e, no limite, os cidadãos, organizados em coletividades - passam a se auto-administrar em termos de política cultural. As coletividades locais tornam-se livres para eleger os responsáveis por suas escolhas, independentemente dos poderes centrais estaduais ou federais." (COELHO, 2004, P. 147)
}

Ao discutirmos a descentralização do programa Cultura Viva, devemos considerar diminuir a concentração desproporcional dos Pontos de Cultura no município do Rio de Janeiro, justamente seguindo o intuito inicial do programa de ser acessível e democrático.

\section{Conclusão.}

O fio condutor desta discussão é analisar como, após a constituição de 1988 e o abandono do modelo de estado centralizador e desenvolvimentista presente nos anos da ditadura, houve uma atribuição explícita de novas capacidades fiscais e responsabilidades públicas das unidades federativas, descentralizando o poder da união e o dispersando pelas demais esferas.

Para examinar os determinantes do processo de descentralização das políticas sociais no Brasil, Arretche (2011) considerou três variáveis de tipo institucional: o legado das políticas prévias, as regras constitucionais que normatizam a oferta de bens e serviços e a engenharia operacional inerente à sua prestação. Estas são atributos das políticas, o que significa dizer que se comportam de modo distinto para cada política social considerada. No Rio de Janeiro, a descentralização promovida pelo programa Cultura Viva não significou desconcentração dos seus Pontos de Cultura, tornando evidente a necessidade de uma investigação nos fatores que causaram esta discrepância.

\section{Referências Bibliográficas:}

ARRETCHE, M. Estado federativo e politicas sociais: determinantes da descentralização. Rio de Janeiro: Revan, 2011. (Obra completa)

BARROS, J. M. ; ZIVIANI, P. O Programa Cultura Viva e a Diversidade Cultural. In: 
BARBOSA, F.; CALABRE, L. Pontos de Cultura: Olhares sobre o programa Cultura Viva. Brasília: Ipea, 2011. (Capítulo de livro)

BELING, J. X. Políticas Culturais. Ponto de vista. Florianópolis, n. 6/7, p. 79-96, 2004/2005. Disponível em:

〈https://periodicos.ufsc.br/index.php/pontodevista/article/download/1202/1468>. Acesso em: 12 de dezembro de 2017. (artigo em periódico digital)

BRAGA, Isabel. Câmara aprova projeto Cultura Viva para estimular a produção do setor no país. O Globo. Disponível em:<https://oglobo.globo.com/cultura/camara-aprova-projetocultura-viva-para-estimular-producao-do-setor-no-pais-13099731

>. Acesso em: 04/05/2019 (site)

BRASIL. lei no 8313 de 23 de dezembro, 1991 (Lei)

BRASIL. Ministério da Cultura (MinC). Cultura Viva: Programa Nacional de Cultura, Educação e Cidadania. Brasília, 2004. (Lei)

CALABRE, L. Políticas Culturais: um diálogo indispensável. Rio de Janeiro: Casa de Rui Barbosa, 2005. (Obra completa)

COELHO, T. Dicionário Crítico de Políticas Culturais. São Paulo: Iluminuras, 2004. (Obra completa)

DÓRIA, C. Os Federais da Cultura. São Paulo: Biruta, 2003. (Obra completa) 
DORNELLES, P. Identidades Inventivas: Territorialidades na rede Cultura Viva na Região Sul. Tese (Doutorado em Geografia). Instituto de Geociências, Universidade Federal do Rio Grande do Sul. Porto Alegre: 2011. (tese)

PORTAL BRASIL. Cultura recebeu mais de R\$ 1 bi a partir de incentivos fiscais em 2015. Governo do Brasil. Disponível em:<http://www.brasil.gov.br/noticias/cultura/2016/01/cultura-recebeu-mais-de-r-1-bi--apartir-de-incentivos-fiscais-em-2015>. Acesso em: 04/05/2019 (site)

RUBIM, A. A. C. Políticas culturais no Brasil: tristes tradições e enormes desafios. In: Rubim, Antonio Albino Canelas e Barbalho, Alexandre (orgs.). Políticas Culturais no Brasil. Salvador: Edufba, 2007, p.11-36. (capítulo de livro)

SANTOS, E. G. Formulação de Políticas Culturais: as Leis de Incentivo e o programa cultura viva. In: BARBOSA, F.; CALABRE, L. Pontos de Cultura: Olhares sobre o programa Cultura Viva. Brasília: Ipea, 2011. (capítulo de livro)

SODRÉ, N. W. Síntese de História da Cultura Brasileira. São Paulo: Difel, 1985. (Obra completa)

TURINO, C.. Ponto de Cultura, o Brasil de baixo para cima. São Paulo: Anita Garibaldi, 2009. (Obra completa)

VENTURA, T. Notas sobre política cultural contemporânea. Revista do Rio de Janeiro, Rio de Janeiro, UERJ, n. 15, 2009. (Periódico) 